\title{
O desafio da interculturalidade frente ao desafio do letramento literário
}

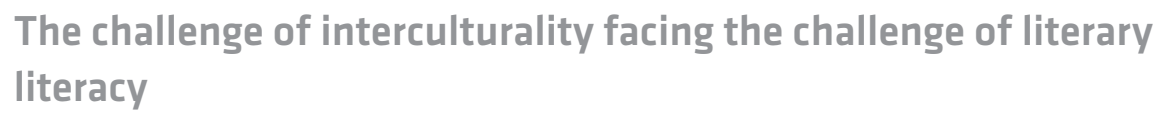

https://doi.org/10.34112/2317-0972a2018v36n74p111-124

\section{Diego Pereira ${ }^{1}$}

ResUmo: Neste artigo, defende-se a escolarização da literatura sob os paradigmas do letramento literário (COSSON, 2016 [2006]) e da compreensão intercultural da realidade (SILVA, 2000; CUCHE, 2002; BUCHOLTZ; HALL, 2004; MAHER, 2007; DANTAS, 2012; MONTIEL, 2013; dentre outros), como resposta à desarmonia definidora da sociedade brasileira pós-moderna, traduzida pelo paradoxo do máximo da racionalidade técnica e do máximo da irracionalidade comportamental (CANDIDO, 2011 [1988]). Para tanto, reconhece-se, no caso do primeiro paradigma, e propõe-se, no do segundo, alguns de seus princípios socioeducativos; problematizando, ainda, as funções sociais creditadas à literatura e à sua escolarização diante das ideologias linguísticas às quais naturalmente se filiam (MAKONI; PENNYCOOK, 2012), de sua difusão no âmbito das principais agências de letramento institucionais (a exemplo da escola e da igreja) e de seu emprego potencial na formação discursiva da nação (EAGLETON, 2006 [1983]; CANDIDO, 2011 [1988]).

Palavras-chave: Escolarização da literatura; letramento literário; interculturalidade.

AвSTRACt: This article advocates for literary education based on the paradigms of literary literacy (COSSON, 2016 [2006]) and of the intercultural understanding of reality (SILVA, 2000; CUCHE, 2002; BUCHOLTZ; HALL, 2004; MAHER, 2007; DANTAS,

1. Universidade Estadual de Campinas, Campinas, SP, Brasil. 
2012; MONTIEL, 2013, among others), as a response to defining unbalances in the post-modern Brazilian society. These translate into a paradox between the highest technical rationality and the highest behavioral irrationality (CANDIDO, 2011 [1988]). To that end, we recognize in the first paradigm and want to implement in the second some of its socio-educational principles. We also want to question the social roles assigned to literature and literature education by analyzing: the linguistic ideologies to which they are naturally connected (MAKONI; PENNYCOOK, 2012); their dissemination in major institutional literacy agencies (for example, schools and the church); and their potential use in structuring the Nation's discourse (EAGLETON, 2006 [1983]; CANDIDO, 2011 [1988]).

KEYWORDS: Literary education; literary literacy; interculturality.

OS INCONTESTES DESAFios DO LETRAMENTO LITERÁRIO E DA COMPREENSÃO INTERCULTURAL DA REALIDADE NA ESCOLARIZAÇÃO DA LITERATURA

Já na década de 1980, Candido (2011 [1988]) constata a existência do paradoxo do máximo da racionalidade técnica e do máximo da irracionalidade comportamental, quando o progresso é perseguido/alcançado sem o desenvolvimento social, apesar de apoiar-se em uma tecnologia capaz de permitir justamente o oposto. Trata-se, em outras palavras, da desarmonia definidora da sociedade daquela época e, de certo modo, da atual, cuja solução, ainda de acordo com o mesmo autor, perpassa a conquista e a manutenção dos direitos humanos, dentre os quais, o da arte e o da literatura, a serem garantidos em sua dimensão fruitiva a todos, indistintamente. E, aqui, essa premissa importa porque parece provar a urgência de se discutir, sobre a escolarização da literatura, seu emprego potencial/real na resposta a questões sociais como a supracitada, a partir do que proscrevem/sancionam a esse respeito as correntes teórico-metodológicas de sua inscrição, que acabam promovendo-a com ou sem a assunção desse desafio.

Atribuir à leitura e à escrita literárias, por exemplo, um caráter apenas estético ou um caráter estético e ético (vide Quadro 1), quando de sua abordagem didático-pedagógica, implica percursos e efeitos educativos diversos e, neste caso, naturalmente opostos. Por meio dessa escolha, pode-se requerer/alcançar uma experiência estética alienante ou libertadora, além de aberta ou fechada à compreensão histórico-cultural da realidade, favorecida/garantida ao indivíduo para que este possa/consiga ver(-se) e sentir(-se) ou ver(-se), sentir(-se) e engajar(-se), conforme advertem 
Candido (2011 [1988]) e Eagleton (2006 [1983]). E, nisso, há sempre uma opção política, sobre a qual incidem formas distintas "de governar" e "de instruir" - mais ou menos liberais, mais ou menos progressistas (ainda que veladas).

\begin{tabular}{|c|c|c|}
\hline & Caráter estético ${ }^{2}$ & Caráter estético e ético \\
\hline Concepção de arte/literatura & $\begin{array}{l}\text { - Objeto imutável (bem com- } \\
\text { pressível) }\end{array}$ & $\begin{array}{l}\text { - Objeto mutável (bem incom- } \\
\text { pressível) }\end{array}$ \\
\hline $\begin{array}{l}\text { Finalidade da produção/re- } \\
\text { cepção artístico-literária }\end{array}$ & $\begin{array}{l}\text { - Captura/revelação do obje- } \\
\text { to artístico-literário (em suas } \\
\text { estruturas mais íntimas); } \\
\text { - Decomposição da experiên- } \\
\text { cia humana; } \\
\text { - Enriquecimento do homem e } \\
\text { da sociedade }\end{array}$ & $\begin{array}{l}\text { - Variada, incluindo a de cap- } \\
\text { tura/revelação do objeto ar- } \\
\text { tístico-literário; } \\
\text { - Explicação/revolução da ex- } \\
\text { periência humana; } \\
\text { - Humanização do homem e } \\
\text { da sociedade }\end{array}$ \\
\hline $\begin{array}{l}\text { Inscrição da produção/recep- } \\
\text { ção artístico-literária nas rela- } \\
\text { ções sociais e seus significados } \\
\text { ideológicos (projeto político- } \\
\text {-social) }\end{array}$ & $\begin{array}{l}\text { - Dispensável (experiência lite- } \\
\text { rária fechada à realidade his- } \\
\text { tórico-cultural, cujos efeitos } \\
\text { sãos temidos) }\end{array}$ & $\begin{array}{l}\text { - Indispensável (experiência li- } \\
\text { terária aberta à realidade his- } \\
\text { tórico-cultural, cujos efeitos } \\
\text { são preconizados) }\end{array}$ \\
\hline $\begin{array}{l}\text { Modo de resposta à inscrição } \\
\text { da vida humana no estado de } \\
\text { coisas predominante }\end{array}$ & $\begin{array}{l}\text { - Para confirmação e apoio } \\
\text { a esse estado, a despeito de } \\
\text { suas contradições }\end{array}$ & $\begin{array}{l}\text { - Para negação, denúncia e } \\
\text { combate a esse estado, quan- } \\
\text { do e se necessário }\end{array}$ \\
\hline Tipo de indagação suportada & - Racional & - Crítica racional \\
\hline $\begin{array}{l}\text { Tipo de experiência estética } \\
\text { requerida }\end{array}$ & - Alienante, estranguladora & - Libertadora \\
\hline $\begin{array}{l}\text { Modo de abordagem da arte/ } \\
\text { literatura no ambiente escolar }\end{array}$ & $\begin{array}{l}\text { - Equipamento intelectual e } \\
\text { social proscrito, garantido ao } \\
\text { indivíduo para ver(-se) e sen- } \\
\text { tir(-se) - maior eficácia esté- } \\
\text { tica, menor eficácia humana }\end{array}$ & $\begin{array}{l}\text { - Equipamento intelectual e } \\
\text { social sancionado, garantido } \\
\text { ao indivíduo para ver(-se), } \\
\text { sentir(-se) e engajar(-se) } \\
\text { - menor eficácia estética, } \\
\text { maior eficácia humana }\end{array}$ \\
\hline Uso político & $\begin{array}{l}\text { - Forma A de governar e ins- } \\
\text { truir }\end{array}$ & $\begin{array}{l}\text { - Forma B de governar e ins- } \\
\text { truir }\end{array}$ \\
\hline
\end{tabular}

Quadro 1 - Natureza das reflexões sobre o lugar da arte/literatura na vida humana - Fonte: Elaboração do autor, com base em Candido (2011 [1988]) e Eagleton (2006 [1983])

2. Estética tomada em sua concepção moderna. 
Nesse sentido, a perspectiva do letramento literário parece contribuir à atenuação da desarmonia social retratada por Candido (2011 [1988]) ou, ainda, a outras a ela relacionadas, pelo desafio didático-pedagógico que sugere aos professores da educação básica. Para Cosson (2016 [2006], p. 12), ela corresponde ao "processo de letramento que se faz via textos literários", capaz de garantir aos alunos seu efetivo domínio, em uma comunidade de leitores formada, a princípio na escola, para experienciar o mundo a partir de suas próprias descobertas; e consiste em favorecer o exercício da leitura e da escrita de textos literários de tal modo que cada aluno possa “[...] [desvelar] a arbitrariedade das regras impostas pelos discursos padronizados da sociedade letrada e [...] [construir] um modo próprio de se fazer dono da linguagem" (COSSON, 2016 [2006], p. 16). Isto é, desde que se conceba a experiência da literatura como "a incorporação do outro em mim sem renúncia da minha própria identidade" (COSSON, 2016 [2006], p. 17), cuja função essencial, portanto, é a de "construir e reconstruir a palavra que humaniza" (COSSON, 2016 [2006], p. 23), fornecendo "os instrumentos necessários para conhecer e articular com proficiência o mundo feito linguagem" (COSSON, 2016 [2006], p. 30).

No entanto, para tal, não basta assumir como objetivo didático-pedagógico a aprendizagem da literatura (da experiência literária, nas atividades de leitura e escrita), a aprendizagem sobre a literatura (de sua história, teoria e crítica) e a aprendizagem a partir da literatura (do conhecimento por ela suportado ou das habilidades e competências por ela favorecidas). Tampouco, optar por um método de ensino baseado nas teorias conciliatórias de leitura, em que a atividade leitora seja reconhecida e proposta no interior da prática social que medeia e transforma as relações humanas. Todas essas alternativas, quando da escolarização da literatura, melhor servirão ao propósito educativo do letramento literário se associadas àquelas da compreensão intercultural da realidade.

De acordo com Dantas (2012), a compreensão intercultural da realidade, desafio acentuado pelas especificidades da globalização no século XXI, requer o diálogo intercultural tal como proposto pela Unesco em 2009: um empreendimento fundamentalmente assentado no reconhecimento da permeabilidade das fronteiras culturais, da relativa agência dos indivíduos nesse contexto, da natureza universal dos direitos humanos, e atento a sua mercantilização local e global. Aqui, talvez seja válido esclarecer - como o faz a autora - que, dada a existência de várias definições para interculturalidade (cada uma condicionada social e historicamente e com suas 
implicações políticas), é possível referir-se a ela como o "contato entre pessoas de culturas distintas, de universos simbólicos compartilhados" (DANTAS, 2012, p. 16).

Essa definição traz consigo a "necessidade de privilegiar o diálogo, a vontade da inter-relação e não da dominação" (DANTAS, 2012, p. 17), além de não se opor ao fato de que "o contato entre culturas é antes fator de conflito do que de sinergia" (HOFSTED, 1997 apud DANTAS, 2012, p. 18) e servir àqueles que buscam entender como o conflito resultante do contato entre culturas tem se tornado mais intenso e complexo "com os deslocamentos cada vez mais rápidos em tempos de globalização capitalista industrial, [...] [para a apropriação] dessa realidade de forma profunda e efetiva de maneira a problematizar e superar formulações baseadas em relações assimétricas e de dominação" (DANTAS, 2012, p. 19).

No Brasil atual, por exemplo, avolumam-se os conflitos entre variados grupos que expressam a produção social da identidade e da diferença. Quando do estabelecimento da Base Nacional Comum Curricular para a Educação Infantil, o Ensino Fundamental e o Ensino Médio (2015-2017), a sociedade dividiu-se entre aqueles apoiadores da inclusão da diferença na pauta educacional, garantindo a sua abordagem no âmbito escolar, sob o objetivo de problematizá-la, e aqueles apoiadores da inclusão da pluralidade e da diversidade, sob o objetivo de valorizá-las - com a vitória do segundo grupo ${ }^{3}$.

O próprio empoderamento de determinados grupos minoritários/minoritarizados, dentre os quais, o de expressão LGBTQ $+{ }^{4}$ e feminista, que se aperceberam da importância desse processo ${ }^{5}$, culminou em novas tensões: movimentos a favor e contrários à legalização do casamento gay, à equiparação legal de direitos civis entre casais homossexuais e heterossexuais (como o da herança e o da adoção), à criminalização da homofobia, à tipificação legal do feminicídio enquanto crime de homicídio qualificado, à legalização do aborto etc. E ainda há determinados

3. Justifica essa distinção dos grupos a perspectiva de multiculturalismo por eles adotada, se crítica ou acrítica, sob a qual defende-se uma determinada concepção de cultura, se "um sistema compartilhado de valores, de representações e de ação" ou "um conjunto de atributos essencializados, imutáveis e unívocos" (MAHER, 2007, p. 261).

4. Grupo minoritarizado de pessoas cujas identidades de gênero e/ou orientações sexuais divergem daquelas padronizadas sócio-historicamente. O acrônimo visibiliza lésbicas, gays, bissexuais, travestis/ transexuais e queers.

5. Segundo Maher (2007, p. 257), o empoderamento constitui-se de três cursos de ação, por parte dos grupos minoritários/minoritarizados, a saber: "(1) de sua politização; (2) do estabelecimento de legislações a ele favoráveis; e (3) da educação do entorno para o respeito à diferença”. 
segmentos da sociedade civil organizada lançando-se à proscrição ou à sanção das manifestações político-sociais, inclusive artístico-literárias, que objetam à manutenção do estado de coisas predominante, no âmbito de aparelhos como o escolar e o artístico - ao menos, assim, permitem ilustrar os programas Escola sem Partido e Escola Livre 6 . Mas, com o agravante do veto ao empoderamento dos grupos minoritários que o empoderamento dos grupos majoritários naturalmente perpetra.

Diante disso, a escola e a literatura podem servir, não por acaso, à construção de uma experiência cidadã alienante ou libertadora, na medida em que se comprometem também com a compreensão da produção social da identidade e da diferença, embora acabem quase sempre erigidas histórica e culturalmente na primeira possibilidade. De modo que, a julgar pelas funções sociais creditadas ou não à arte/literatura - em parte, devido ao influxo do contexto anteriormente retratado -, cabem, aos professores imbuídos da necessidade de promoção do letramento literário, os seguintes questionamentos, com vistas à ressignificação de sua práxis pedagógica:

A. Por que conceber a literatura como um objeto de caráter meramente estético, imutável em suas estruturas mais íntimas e justificado, no ato de sua produção/ recepção, pela captura/revelação da matéria artística tão somente? Por que não conceber a literatura como um objeto de caráter estético e ético, mutável em suas estruturas mais íntimas e, por isso, justificado, no ato de sua produção/ recepção, pela captura/revelação da matéria artística, dentre outras, como a própria realidade?

B. Quais as implicações políticas de se estabelecer como finalidade da produção/ recepção artístico-literária a decomposição da experiência humana, para o enriquecimento do homem e da sociedade, em vez da explicação/revolução dessa experiência, para a humanização de ambos?

C. A que propósito(s) didático-pedagógico(s), filosófico-histórico(s) e político-educacional(is) serve a inscrição ou a não-inscrição da produção/recepção

6. Ambos os programas constituem projetos de lei em tramitação no Brasil sobre a abrangência da liberdade dos professores quanto às suas opções teórico-metodológicas, que, inscritas, invariavelmente, em um quadro político-ideológico, devem, ou não, explicitá-lo. Neste caso, é debatida a pertinência de sua livre expressão de pensamento e ideias, nos âmbitos político-ideológico, artístico-cultural e/ou filosófico-religioso, quando do próprio exercício profissional. A esse respeito, a perspectiva do programa/projeto de lei Escola sem Partido é a da proscrição; e, a do Escola Livre, a da sanção. 
artístico-literária nas relações sociais e seus significados ideológicos? Ou, por que desvincular a experiência de leitura e de escrita proporcionada pela literatura da compreensão histórico-cultural da realidade que ela suporta?

D. De que modo justificar a produção/recepção artístico-literária ante a inscrição da vida humana no estado de coisas predominante? Para a confirmação e o apoio a esse estado, a despeito de suas contradições, ou a sua negação, denúncia e combate, quando e se necessário?

\section{Alguns Dos PRINCípios SOCIOEdUCATIVOS IMPLiCAdos NA COMPREENSÃO INTERCULTURAL DA REALIDADE}

Os questionamentos anteriores, que buscam vincular o ensino de literatura também à compreensão intercultural da realidade, especialmente quando inscrito no paradigma do letramento literário, são propostos a partir de alguns princípios extraídos do paradigma do multiculturalismo crítico. De acordo com Maher (2007), que apresenta e discute o segundo, as escolas, cujas práticas refletem em sua grande maioria modelos de pensamento eurocêntricos, têm por grande desafio a reinvenção de seu papel, historicamente por elas desempenhado, para a assimilação dos grupos sociais minoritários por aqueles majoritários. O que implica comprometerem-se em deslegitimar a hegemonia expressa nas crenças, valores e conhecimentos até então promovidos no âmbito de suas ações; mas, não só. É preciso, também, que os seus objetos e instrumentos de ensino traduzam uma concepção de cultura oposta à de "conjunto de atributos essencializados, imutáveis e unívocos" (MAHER, 2007, p. 261) - em nome da qual foram criados projetos coloniais e de estado-nação -; sem, no entanto, promover qualquer separatismo/guetização cultural.

Nesse sentido, professores e estudantes podem/devem "tentar entender por que diferentes grupos humanos acreditam no que acreditam, agem do modo como agem" (MAHER, 2007, p. 262), em um projeto socioeducativo similar àquele proposto por Maher (2007, p. 267): o da "educação do entorno para diferença linguística e cultural". Porque, a despeito da especificidade de sua motivação (esclarecer as exigências da educação plurilíngue, de expressão intercultural, destinada aos grupos minoritários, para, em especial, garanti-la), os pré-requisitos à sua realização parecem aplicáveis às práticas de letramento literário aqui defendidas. São eles: "a necessidade de aprender a aceitar o caráter mutável do outro" (oposição à cristalização de identidades) e "a necessidade de destotalizar o outro" (oposição à 
adoção de padrões culturais modelares) (MAHER, 2007, p. 267). E atentar para os mesmos, no processo educativo, significa assumir a diferença enquanto um objeto do trabalho didático-pedagógico, com vistas à sua problematização, através do "exame da própria cultura” (CHIODI; BAHAMONDES, 2001 apud MAHER, 2007, p. 268) - algo que se revela indispensável à formação cidadã dos estudantes, apesar da natureza controversa desse princípio nos documentos curriculares oficiais, pois, como adverte Maher (2007, p. 268):

[...]. Quando o aluno toma consciência de que a nação brasileira é produto de relações interculturais, quando ele se vê confrontado com a mutabilidade, a hibridez, a não-univocidade de sua própria matriz cultural, é mais fácil ele perceber que está operando com representações sobre o outro e que as representações que faz das culturas e dos falares minoritários não são nunca verdades objetivas ou neutras, mas, sim, construções discursivas.

A representação é, neste caso, entendida como na perspectiva de Silva (2000): um sistema de significação linguístico e cultural que, inscrito nas relações de poder, ocupa-se da atribuição de sentidos arbitrários e indeterminados a um referente (por meio dela, o mundo passa a existir, tal como concebido, e em suas formas dominantes). De modo que assumir ou refutar essa percepção contribui à desestabilização ou à estabilização das crenças às quais não somente se vincula, mas dá suporte $\mathrm{e}$ sustentação no ato de produção social da identidade e da diferença. Uma pedagogia e um currículo descompromissados quanto ao questionamento da indeterminação, da ambiguidade e da instabilidade de todo e qualquer sistema representacional revelam-se, no mínimo, liberais: celebram a diversidade em detrimento da problematização da diferença, sob uma perspectiva de tolerância e respeito que parecem não cumprir sua promessa, devido, em parte, à naturalização, cristalização e essencialização das identidades cultural e social em suas diversas dimensões (SILVA, 2000).

Diante da produção da identidade e da diferença, cabe à escola "tratar as relações entre as diferentes culturas não como uma questão de consenso, de diálogo ou comunicação, mas como uma questão que envolve, fundamentalmente, relações de poder" (SILVA, 2000, p. 96). Sobretudo, para que os alunos criem e recriem a sua cultura, com relativa criticidade e autonomia, na atribuição de sentido ao próprio mundo social, engajando-se, de modo mais reflexivo, na disputa e na luta próprias desse processo. Compreendendo como a diferença é ativamente produzida, eles poderão respeitá-la e admiti-la de fato, já que o reconhecimento e a celebração 
da mesma sem o seu devido questionamento mostram-se vazios, conforme Silva (2000, p. 100) permite constatar, acrescentando, ainda, que:

os estudantes e as estudantes deveriam ser estimulados, nessa perspectiva, a explorar as possibilidades de perturbação, transgressão e subversão das identidades existentes. [...]. Estimular, em matéria de identidade, o impensado e o arriscado, o inexplorado e o ambíguo, em vez do consensual e do assegurado, do conhecido e do assentado. Favorecer, enfim, toda experimentação que torne difícil o reforço do eu e do nós ao idêntico.

Talvez seja esse o maior desafio da escola, mesmo: contribuir para que se perturbe, transgrida e subverta qualquer forma de pensamento hegemônico sob o qual a vida reduz-se a um modelo que, tradutor dos interesses dos grupos majoritários, acaba oficialmente promovido. Ao menos, a julgar pelos efeitos da globalização em seu estágio mais recente sobre a dinâmica da língua e da cultura na sociedade, dentre os quais: (1) a intensificação e a qualificação das interações humanas, mas em ritmos distintos (o primeiro processo, mais acelerado; o segundo, menos), (2) a compressão da experiência humana porque comprimidos também o espaço e o tempo, (3) a interconexão entre indivíduos e grupos sociais diferentes, seus municípios, estados e países, por vezes, conflitiva e (4) o entrelaçamento das realidades local e global, com as suas causas e efeitos político-econômicos (RUDBY; ALSAGOFF, 2014).

Daí a importância de se aproximar das discussões de Silva (2000), Cuche (2002), Bucholtz e Hall (2004) e Montiel (2013): para melhor compreender as ideologias linguístico-culturais próprias da globalização recente, as tensões entre aquelas proscritas e sancionadas na construção das identidades individual e coletiva, e as causas e os efeitos político-sociais da inclusão ou exclusão desse tema na pauta educacional, sobretudo quando da elaboração de currículos em quaisquer fases, níveis e contextos. Essa interseção teórica permite dimensionar o desafio imposto pela globalização à escola, por seus efeitos à dinâmica linguístico-cultural da sociedade, sugerindo ao professor apercebido de seu papel nesse contexto quais as finalidades socioeducativas da compreensão intercultural da realidade - elas são muitas. Genericamente, trata-se de, aos estudantes, o professor:

- Incentivar o inventário e a crítica das representações linguístico-culturais que invariavelmente servem à construção da identidade e da diferença, atentando para o seu caráter performativo (SILVA, 2000). Ou seja, o professor precisa 
conceber as identidades existentes enquanto produto de um ato de enunciação que se repetiu inúmeras vezes porque reconhecível, legível e reutilizável, para, depois, oportunizar aos estudantes a identificação e a análise da cadeia e da eficácia produtiva desses enunciados, os quais poderão vir a ser reforçados ou fragilizados, também a partir de atos performativos, se apontados como responsáveis ou não pela manutenção de identidades hegemônicas e, o mais importante, se criticados por isso. Afinal, se "a mesma repetibilidade que garante a eficácia dos atos performativos que reforçam as identidades existentes pode significar também a possibilidade da interrupção das identidades hegemônicas" (BUTLER, 1999 apud SILVA, 200o), por que não a utilizar nesse empreendimento?

- Sugerir o questionamento das diferentes identidades culturais que, neles e/ou em seus grupos sociais, se entrecruzam, como decorrência de sua história, relacionando-as a outras, de indivíduos e grupos diferentes, para a compreensão de seu caráter não apenas misto, sincrético e híbrido, mas mutável, multidimensional e manipulatório. O que implica aperceber-se da regulamentação e do controle da monoidentificação que o Estado perpetra, ao defender a construção de uma identidade nacional, na tentativa de se fechar a quaisquer inovações político-sociais favorecedoras da descentralização e da desburocratização do poder (CUCHE, 2002). Para tanto, seria preciso considerar as concepções de cultura e identidade reconhecidas por Cuche (2002), a saber: a objetiva, a subjetivista e a relacional/situacional, sendo que deve o professor fundamentar-se na última. Mas, veja por quê. $\mathrm{Na}$ concepção objetivista, a identidade assume o status de natureza humana, que se herda biológica ou étnico-culturalmente, preexistindo, portanto, ao indivíduo, o qual pertence por essência a um grupo original, cultural ou étnico. Em todos os casos, sua identificação em relação a esse ou àquele grupo é automática, definitiva. Por isso, esse indivíduo e o seu grupo podem ser radicalmente separados de outros. $\mathrm{Na}$ concepção subjetivista, a identidade assume o status de construção humana, uma coletividade forjada pelos indivíduos que escolhem ou pensam escolher aquilo que são; dependente dessa subjetividade, ela é uma ilusão e seu caráter, efêmero. $\mathrm{Na}$ concepção relacional/situacional, a identidade assume o status de construção e/ ou reconstrução humana, existindo sempre em relação a uma outra, diante da qual diferencia-se/busca diferenciar-se. Ela surge no interior das práticas sociais, como expressão da disputa pelo poder entre autoidentificação e hetero-identificação dos indivíduos, que agem desse ou daquele modo de acordo com a posição ocupada nesse sistema de relações. 
- Não inviabilizar a compreensão linguístico-cultural das relações de poder nas quais as identidades são enredadas, privando-os de explorarem os complexos significados sociais e políticos operados pela língua na marcação da semelhança e da diferença entre os indivíduos e seus grupos de filiação identitárias, cujas ações habituais resultam naturalizadas ou não (BUCHOLTZ; HALL, 2004).

- Favorecer a articulação de suas identidades e a expressão de suas preocupações, em um exercício dialógico que, sustentado por valores universalmente compartilhados, lhes sirva para o reconhecimento das próprias diferenças, não hierarquizadas, através da autocrítica (MONTIEL, 2013). Aqui, o pensamento crítico pressupõe "um processo ativo de interpretações de significados dentro de um contexto cultural, social e histórico específico, que permite aos indivíduos fazer frente aos desafios da vida cotidiana" (MONTIEL, 2013, p. 31), como resposta às "informações ideologizadas que alienam” (MONTIEL, 2013, p. 50); devendo surgir no encontro de uns com os outros, no/para o estabelecimento da convivência pacífica.

AS FUNÇÕES SOCIAIS CREDITADAS À LITERATURA E À SUA ESCOLARIZAÇÃO NA FORMAÇÃO DISCURSIVA DA SOCIEDADE

Naturalmente, as funções sociais creditadas à literatura e à sua escolarização, dentre as quais, a da compreensão intercultural da realidade, como defendida neste artigo, podem e devem ser questionadas. Mas porque respondem às ideologias linguísticas, que, forjadas no interior de uma determinada comunidade, nação e/ou da própria humanidade, referem-se a um sistema cultural de ideias sobre a língua, a sociedade e a sua relação, investido de interesses fundamentalmente políticos, a exemplo da manutenção da cultura, em seu caráter hegemônico (MAKONI; PENNYCOOK, 2012). Fechar-se a essa constatação (aqui, estendida à literatura) é, de certo modo, negar a construção histórico-social da língua (em suas variadas manifestações, como a literária), utilizando-a e a compreendendo fora das preocupações humanas que a justificam e, portanto, da mudança política que ela pode vir a proporcionar, se explorada também sob essa potencialidade.

Em relação à literatura, Eagleton (2006 [1983]) sugere, inclusive, qual o seu papel no projeto de formação discursiva da sociedade, ao menos a partir do que observa sobre a realidade inglesa, inscrita antes e depois do século XIX. É sua a constatação de que o papel manifesto pela experiência literária, nas atividades de produção e/ou recepção, parece ser, independentemente do tempo de sua inscrição, 
o de resguardar a humanidade, pronunciando-se a respeito das verdades imprescindíveis à sua manutenção ou à sua transformação; não importando qual a natureza do objeto literário reconhecida nessa ou naquela época (se condicional, porque definido no contexto valorativo da recepção; ou, constitutiva, no contexto formal da produção), tampouco a motivação aplicada à sua produção/recepção (de ater-se à dimensão fatual da realidade ou rompê-la criativa e imaginativamente). Pois, a despeito das especificidades do emprego da literatura na sociedade inglesa do período, da experiência de fruição literária que cada um desses momentos suportou e admitiu, as ideologias literárias mais difundidas no âmbito das principais agências de letramento vinculadas à política nacional, como a igreja e a escola, serviram a interesses sociais muito estritos, notadamente aqueles da classe burguesa.

Conforme defende Eagleton (2006 [1983]), o exercício da leitura e/ou da escrita literárias ao qual se pode chegar, entre as sanções e as proscrições dessas agências, acaba por corresponder a uma experiência mais alienante e menos libertadora - ainda que garantido sob os princípios da unidade ou da diversidade. Nesse sentido, qualquer modelo de fruição, se homogeneizante, se heterogeneizante, é estabelecido para responder aos valores sociais que, vigentes em uma dada época, são passíveis de maior aprofundamento e disseminação. Mas, com um agravante: quando esses valores se revelam hegemônicos, ler/escrever literatura importa para assimilá-los, devendo esse exercício ser promovido para o desencadeamento de uma reação comum entre leitores/escritores diante dos fatos histórico-culturais por eles vivenciados; quando não, para transcendê-los (aqui, esses leitores/escritores são levados a uma reação pessoal, desprovida de coletividade). Dito de outro modo, a literatura é desobscurecida e obscurecida na história muito convenientemente: ao incorporar a voz dos governantes, existe no centro das práticas socais; ao incorporar a voz do povo, existe à margem; ela também subsidia o projeto de formação discursiva da sociedade.

Agora que, no Brasil, é lançada a Base Nacional Comum Curricular, revela-se no mínimo curiosa a redução da experiência estética ao reconhecimento, à valorização e à fruição das manifestações artístico-culturais, em sua diversidade. Como se a formação do leitor literário devesse implicar, apenas, o conhecimento e a apreciação de variadas obras das literaturas nacional/estrangeira e local/global, para a captura da singularidade destas em suas estruturas mais íntimas, sem a compreensão intercultural da realidade que a produção/recepção literária pode favorecer. As finalidades, neste caso, não são práticas (ainda que se possa questionar esse utilitarismo), mas artísticas. Por meio da literatura, deve-se viver mundos ficcionais; quando muito, ampliar a visão 
de mundo - desde que "pela experiência vicária com outras épocas, outros espaços, outras culturas, outros modos de vida, outros seres humanos" (BRASIL, 2017, p. 65).

A época atual, com seus espaços, seres humanos e culturas, parece evitada; e, de tal modo, que "a escolha dos textos para leitura pelos alunos deve ser criteriosa, para não expô-los a mensagens impróprias ao seu entendimento, consoante determinam os Artigos 78 e 79 do Estatuto da Criança e do Adolescente (Lei no 8.069/1990)" (BRASIL, 2017, p. 65). Há quem acredite ser essa uma medida curricular, portanto socioeducativa, para a preservação da integridade física, psíquica e moral dos estudantes diante de quaisquer textos que, alusivos ou tradutores da pornografia, obscenidade, alcoolismo, tabagismo, armamento, possam corrompê-los. No entanto, há quem acredite em outro objetivo, como o de levá-los a respeitar o estatuto da pessoa e da família, sob os valores sociais de sua construção, mormente aqueles hegemônicos. Qualquer reportagem sobre a realidade brasileira mais recente, seus conflitos socioculturais definidores, permite não só a justificativa, mas a complexificação desse debate. Em novembro de 2017, por exemplo, o El País o incita: "Vocês entendem o que é matar uma pessoa só porque ela é diferente?” (BETIM, 2017).

\section{REFERÊNCIAS}

BETIM, F. Vocês entendem o que é matar uma pessoa só porque ela é diferente?. El País, São Paulo, 15 nov. 2017. Disponível em: <https://goo.gl/H2uayx >. Acesso em: 25 nov. 2017.

BRASIL. Lei no 8.069, de 13 de julho de 1990. Dispõe sobre o estatuto da criança e do adolescente e dá outras providências. Portal da Legislação da Presidência da República, Brasília, DF. Disponível em: <https://goo.gl/JapbdX>. Acesso em: 25 nov. 2017.

. Ministério da Educação. Secretaria de Educação Básica. Base nacional comum curricular: proposta preliminar: terceira versão. Brasília: MEC, SEB, 2017. Disponível em: <https://goo.gl/ $\mathrm{mSSvBb}>$. Acesso em: 25 nov. 2017.

BUCHOLTZ, M.; HALL, K. Language and identity. In: DURANTI, A. (Org.). A companion to linguistic anthropology. Malden, MA: Blackwell, 2004. p. 369-394.

CANDIDO, A. (1988). O direito à literatura. In: . Vários escritos. 5. ed. Rio de Janeiro: Ouro sobre Azul, 2011. p. 171-193.

COSSON, R. (2006). Letramento literário: teoria e prática. 2. ed. São Paulo: Contexto, 2016.

CUCHE, D. Cultura e identidade. In: . A noção de cultura nas ciências sociais. Tradução: Viviane Ribeiro. 2. ed. Bauru: EDUSC, 2002. p. 175-202.

DANTAS, S. D. Para uma compreensão intercultural da realidade. In: (Org.). Diálogos interculturais: reflexões interdisciplinares e intervenções psicossociais. São Paulo: IEA/USP, 2012. p. 15-23. 
EAGLETON, T. (1983). Teoria da literatura: uma introdução. Tradução de Waltensir Dutra. 6. ed. São Paulo: Martins Fontes, 2006.

MAHER, T. M. A educação do entorno para a interculturalidade e o plurilinguismo. In: KLEIMAN, A. B.; CAVALCANTI, M. C. (Org.). Linguística aplicada: faces e interfaces. Campinas, SP: Mercado de Letras, 2007. p. 255-270.

MAKONI, S.; PENNYCOOK, A. Disinventing multilingualism: from monological multilingualism to multilingua francas. In: MARTIN-JONES, M.; BLACKLEDGE, A.; CREESE, A. (Org.). The handbook of multilingualism. London: Routledge, 2012. p. 439-453.

MONTIEL, E. A nova ordem simbólica: a diversidade cultural na era da globalização. In: SIDEKUM, A. (Org.). Alteridade e multiculturalismo. Ijuí, RS: Editora Ijuí, 2013. p. 15-50.

RUBDY, R.; ALSAGOFF, L. The cultural dynamics of globalization: problematizing hybridity. In: . (Org.). The global-local interface and hybridity: exploring language and identity. Bristol: Multilingual Matters, 2014. p. 1-14.

SILVA, T. T. A produção social da identidade e da diferença. In: (Org.). Identidade e diferença: a perspectiva dos estudos culturais. Petrópolis, RJ: Vozes, 2000. p. 73-102.

\section{SOBRE O AUTOR:}

Diego Pereira é licenciado em Letras com Habilitação em Língua Portuguesa e Literaturas (Universidade do Estado da Bahia), especialista em Linguagem, Tecnologia e Ensino (Universidade Federal de Minas Gerais) e mestrando em Linguística Aplicada (Universidade Estadual de Campinas). É Professor da Educação Básica: Língua Portuguesa da Secretaria de Estado de Educação, Esporte e Lazer de Mato Grosso (SEDUC-MT). Tem experiência nas áreas de Letras e Educação, com pesquisa nos seguintes temas: documentos oficiais de prescrição e mediação curricular (perspectiva político-cultural de sua inscrição), sistematização e monitoramento da ação docente (construção/avaliação de dispositivos) e letramento literário (funções sociais creditadas à literatura e à sua escolarização, notadamente no Ensino Médio; além de suas implicações didático-pedagógicas). E-mail:prof.diegopereira@hotmail.com.

Recebido em 17 de fevereiro de 2018 e aprovado em 31 de outubro de 2018. 